\title{
Usage Survey of Personal Underfloor Air Outlet System and Thermal Environment Acceptability
}

\author{
Masanari Ukai ${ }^{1}$, Yoshito $\mathrm{Arai}^{2}$, Mitsuhiro Takahashi ${ }^{3}$, Sei Ito $^{4}$, Saya Amemiya ${ }^{5}$, Gouo Tsusaka ${ }^{6}$, Tatsuo Nobe ${ }^{7}$ \\ ${ }^{1,6,7}$ Kogakuin University, ${ }^{2,3,4,5}$ Shimizu Corporation,
}

\begin{abstract}
This study was aimed to clarify the usage of a personal air-conditioning system and to describe the characteristics of actual worker acceptance of the thermal environment. The results showed that the usage rate of the personal air-conditioning system was $90 \%$ and that most workers were satisfied with the system's effect. Only a few workers reported that the environment was unacceptable despite the use of the system, and they expressed this even when the temperature and humidity were within a comfortable range. It was suggested that the complaints resulted from factors such as the individual thermal histories and changes in their metabolic rate upon returning to the office after performing outdoor activities.
\end{abstract}

Keywords - Personal air-conditioning system, Acceptability, Thermal comfort, Ostracon

\section{INTRODUCTION}

In office spaces, each worker has individual preferences regarding thermal environmental conditions and personal thermal comfort. Usually, not all workers' preferences can be met simultaneously by the conditions in an office building. Indeed, the individual preferences of many workers regarding thermal comfort are not satisfied at all. As a solution to such problems, personal air-conditioning initiatives have recently been introduced in offices to improve the thermal comfort of office workers. These efforts have attracted considerable attention because they have reduced complaints from workers. Using a personal air-conditioning system, each worker can adjust the thermal environment according to his or her preference. However, only a few usage surveys of personal air-conditioning systems have been reported. Here, we conducted a detailed usage survey of a personal underfloor air outlet system at the headquarters of S Corporation [1]. A summary of the general headquarters of $\mathrm{S}$ Corporation is shown in Table I.

\section{SUMMARY OF THE BUILDING AND AIR-CONDITIONING SYSTEM}

This building has been in use since August 2012. It includes an air-conditioning system that separates latent heat and sensible heat based on radiant and desiccant air-conditioning. By controlling temperature, humidity, and airflow separately, the objectives are to realize an air conditioning system with latent sensible separation and environment selection rights in the office and to achieve both energy savings and comfort.
TABLE I

SUMMARY OF THE GENERAL HEADQUARTERS OF S CORPORATION

\begin{tabular}{|l|l|}
\hline Location & Chuo-ward, Tokyo, Japan \\
\hline Ground-floor area & $3,000 \mathrm{~m}^{2}$ \\
\hline Architectual area & $51,800 \mathrm{~m}^{2}$ \\
\hline Construction & Armored concrete, \\
\hline Number of stories & B3F-22F-PH1F \\
\hline Major application & Business office \\
\hline CASBEE & S rank (BEE 9.7) \\
\hline LEED & NC GOLD \\
\hline Completion of construction & May 2012 \\
\hline
\end{tabular}

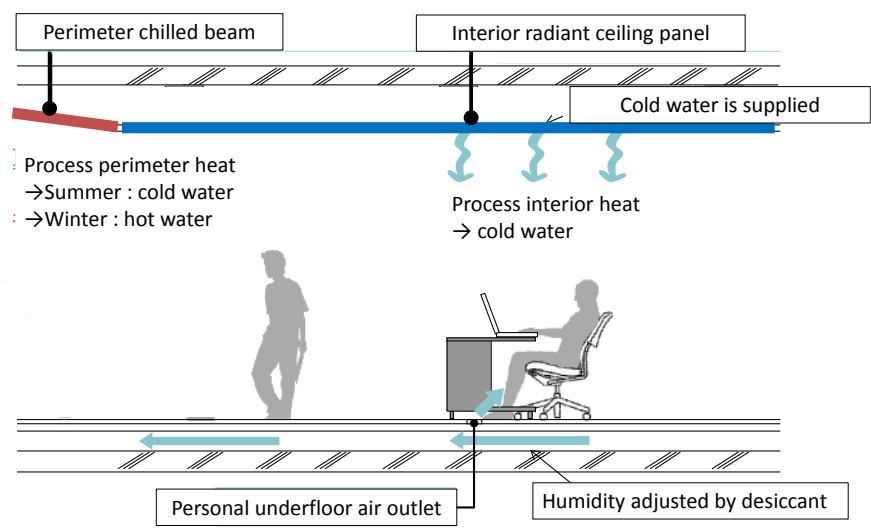

Fig. 1. Air-conditioning system.

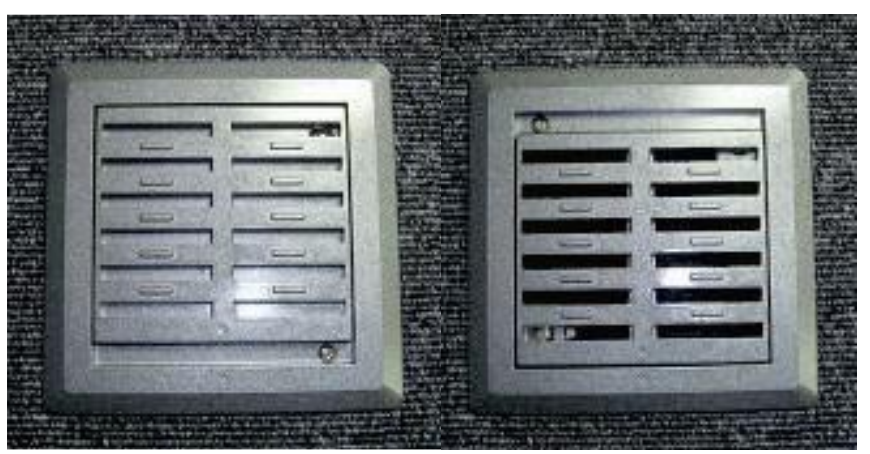

Fig. 2. Personal underfloor air outlet system.

Temperature is controlled by ambient air-conditioning using a radiant ceiling panel. Humidity is supplied by blowing air adjusted with desiccants from under the floor. This desiccant air-conditioning system is operated with a low-temperature reproduction $\left(45{ }^{\circ} \mathrm{C}\right)$ desiccant rotor when dehumidifying. Moisture collected on the desiccant rotor is emitted to the outflow air by reproduction. The waste heat, produced during the manufacture of cold heat by district heating, is used for 
reproduction. This air-conditioning system consists of two low-temperature reproduction desiccant rotors, a pull-down coil (cool coil), a regenerative coil (heat coil), a cold-water coil, and a hot-water coil. The total heat exchanger is set up for primary treatment of the outflow air. Airflow with controlled humidity is supplied by task conditioning based on the personal underfloor air outlet system for each worker. Radiant ceiling panels process the perimeter load by supplying the perimeter zone with cold water in summer and hot water in winter. In the interior zone, cold water is supplied throughout the year to process the internal heat generated from human bodies, lighting, and office equipment. The air-conditioning system is shown in Fig. 1, and the personal underfloor air outlet system is shown in Fig. 2 and Table II. The cooling effect of the personal underfloor air outlet system is shown in Fig. 3. It is defined as the temperature that produces a thermal loss from a thermal mannequin in an environment where the equivalent temperature is actual, and there is an equivalent amount of thermal loss. Moreover, the cooling effect defines it as equivalent temperature-operative temperature. The personal underfloor air outlet produced a cooling effect on the foreleg, front thigh, and back thigh $\left(-0.2{ }^{\circ} \mathrm{C},-0.6{ }^{\circ} \mathrm{C}\right.$, and $\left.-0.5^{\circ} \mathrm{C}\right)$, as can be seen in Fig. 3, whereas the greatest cooling effect $\left(-1.6^{\circ} \mathrm{C}\right)$ was seen at the pelvis.

This study was aimed to clarify the usage of this personal air-conditioning system and to describe the characteristics of actual worker acceptance of the thermal environment through data captured by the Ostracon voting device. This device was developed to record the physical environment when a worker presses a button to register a complaint [2].

\section{MATERIALS/METHODS}

\section{A. Usage recording device of personal underfloor air outlet system}

To conduct this study, we developed a usage recording device that recorded the usage conditions when workers operated the personal underfloor air outlet system. This device is shown in Fig. 4. The structure of the usage recording device was recorded in the voltage data logger when current flowed through a switch on the personal underfloor air outlet system.

\section{B. Ostracon device}

Thermal comfort is a topic that is under considerable debate because of the rapid progress in air-conditioning technology. The thermal index of the American Society of Heating, Refrigerating and Air Conditioning Engineers (ASHRAE) uses two pairs of antonyms: "hot/cold" and "warm/cool." However, such nomenclature is problematic in Japan: ASHRAE describes "warm" and "cool" environments as uncomfortable for daily living, but such environments are sometimes believed comfortable in Japan [3]. Moreover, "neutral" is not always comfortable. The results of a 1975 survey conducted by ASHRAE showed that no single thermal environment satisfied all respondents [4]. Therefore, the environmental condition and physiology referred to as
TABLE II

SUMMARY OF THE PERSONAL UNDERFLOOR AIR OUTLET SYSTEM

\begin{tabular}{|c|c|}
\hline Size & H $110 \mathrm{~mm} \times \mathrm{L} 110 \mathrm{~mm}$ \\
\hline Aperture size & $0.00192 \mathrm{~m}^{2}$ \\
\hline Airflow velocity & $1.6 \mathrm{~m} / \mathrm{s}$ \\
\hline Air volume & $11.1 \mathrm{~m}^{3} / \mathrm{h}$ \\
\hline
\end{tabular}

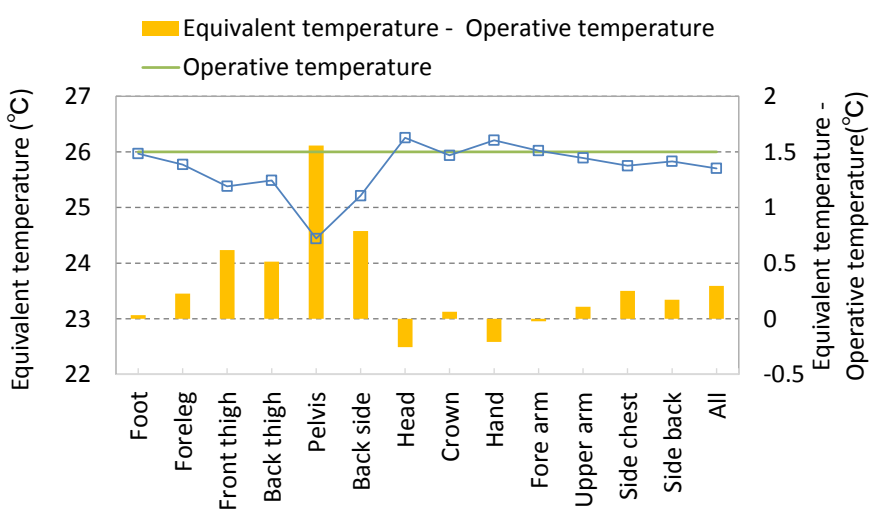

Fig. 3. Cooling effect of the personal underfloor air outlet system.
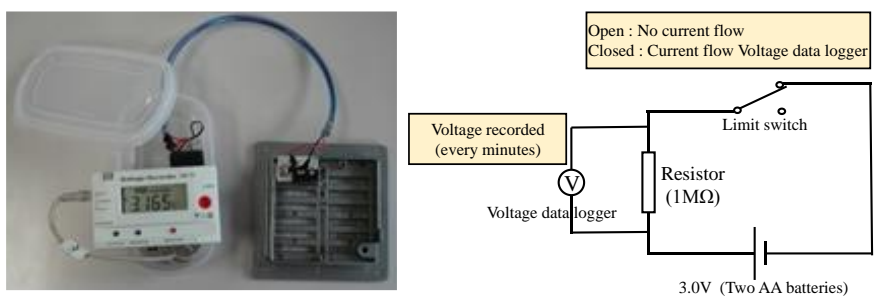

Fig. 4. Usage recording device.

TABLE III

DEVICE USED TO MEASURE ENVIRONMENTAL ACCEPTABILITY (OSTRACON)

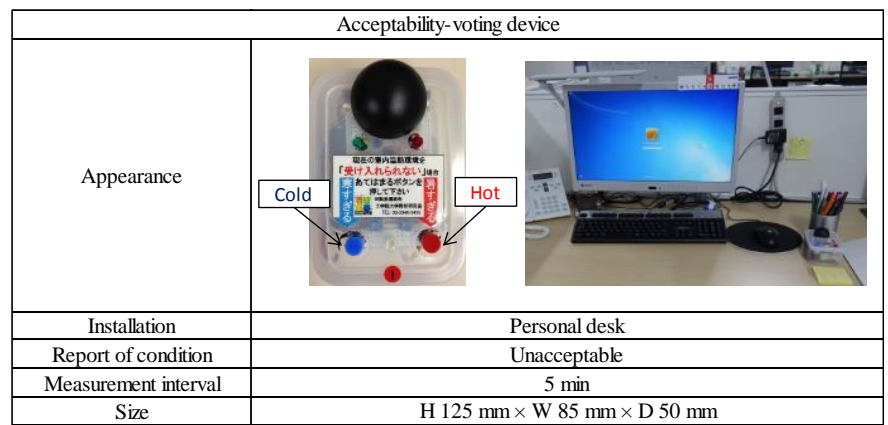

than "warm" or "cool," was determined by ASHRAE as the definition of comfort [5].

Current air-conditioning systems improve the thermal comfort of indoor environments based on this concept. Two indices typically used to evaluate thermal comfort - predicted mean vote and standard effective temperature - evaluate only the steady states of thermal sensation [6]. The predicted percentage of people dissatisfied index is based on a predicted 
mean vote and is used to evaluate the steady-state environment. In reality, such a restriction is problematic because the indoor thermal environment is evaluated based on acceptance by office workers, as expressed through complaints, and no established index exists to evaluate this acceptability.

The term "Ostracon" originated in ancient Greece. It describes a shard of pottery used by the voting public to prevent the election of a dictator. The authors adopted this name for an acceptability-voting device, developed for the present study, to record conditions of the physical environment deemed unacceptable by workers. Table III lists the specifications of the Ostracon device. Workers could press buttons labeled "hot" or "cold" on the device, located on their desks, to record a complaint when they felt that the thermal environment was unacceptable. The Ostracon sent a signal to a pulse recorder when a button was pressed. This activated the connected temperature, globe temperature, and humidity recorders.

A seat-occupancy sensor was also developed to record the temperature of the seat of a chair. The seat-occupancy sensor specifications are shown in Table IV.

The usage recording device was employed in the usage survey of the personal underfloor air outlet system for 20 workers in summer and fall. The summer surveillance period was 24 days, from August 4 to September 10. The fall surveillance period was 11 days, from November 4 to November 27.The Ostracon was also used to measure whether workers felt that the thermal environment was acceptable. This data is deficient because it includes days on which a data logger was being replaced. Moreover, we carried out a questionnaire to survey the degree of satisfaction with the personal underfloor air outlet system. Table $\mathrm{V}$ provides a summary of the subjects.

TABLE IV

SEAT-OCCUPANCY SENSOR

\begin{tabular}{|c|c|}
\hline \multirow{4}{*}{ Appearance } & \multicolumn{3}{|c|}{ Seat occupancy sensor } \\
\hline & \\
& \\
& \\
\hline
\end{tabular}

TABLE V

SUMMARY OF SUBJECTS

\begin{tabular}{|c|c|c|c|c|c|}
\hline \multicolumn{6}{|c|}{ Number of people } \\
\hline \multicolumn{2}{|c|}{ Gender } & \multicolumn{2}{|c|}{ Job category } & \multicolumn{2}{|c|}{ Age } \\
\hline \multirow{2}{*}{ Man } & \multirow{2}{*}{10} & Clerical job & & 20 's & 9 \\
\hline & & Technical job & 12 & 30 's & 4 \\
\hline \multirow{2}{*}{ Woman } & \multirow{2}{*}{10} & Management & 1 & 40 's & 6 \\
\hline & & Research job & & 50 's & 0 \\
\hline
\end{tabular}

\section{RESUlts}

\section{A. Indoor thermal environment}

Fig. 5 shows the data from ASHRAE Standard 55-2004 within an indoor thermal environment during office hours [8]. The red dashed lines indicate the comfortable temperaturehumidity range in summer. The indoor thermal environment was preset at a higher level than usual due to the brownout restrictions set in the aftermath of the great East Japan Earthquake. Also, Fig. 6 shows the data from ASHRAE Standard 55-2004 within an indoor thermal environment during seated times, as it relates to the measured thermal environment in the fall. The red dashed lines indicate the comfortable temperature-humidity range in summer. The blue dashed lines indicate the comfortable temperature-humidity range in winter. During this season, the varying indoor thermal environment was distributed in the comfortable temperaturehumidity range at the standard effective temperature (SET*) in summer.

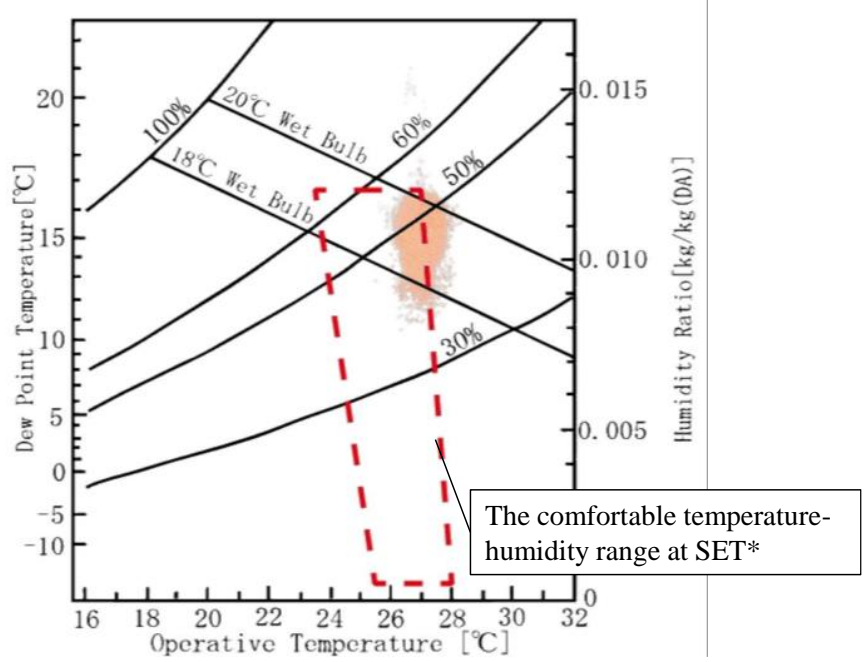

Fig. 5. Indoor thermal environment in summer during operational hours.

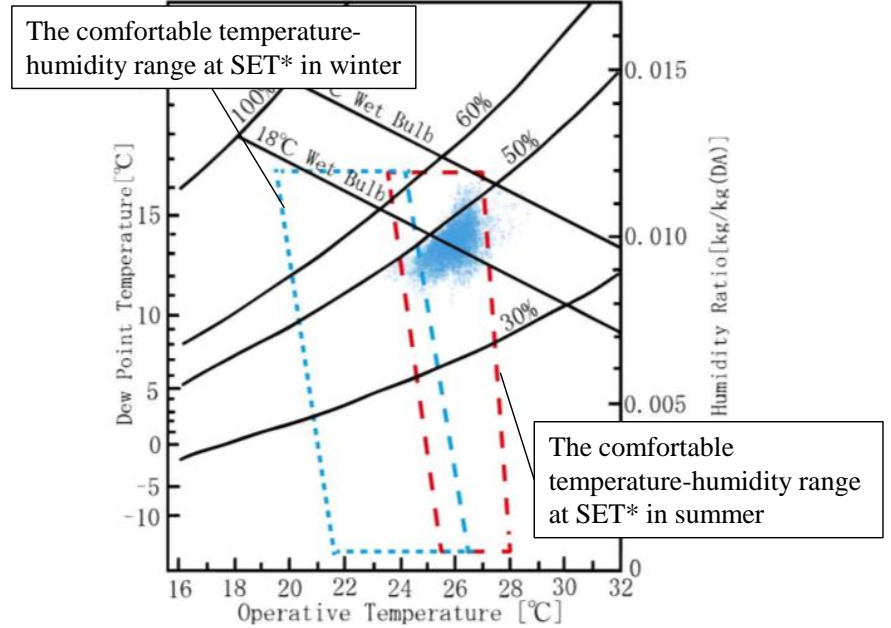

Fig. 6. Indoor thermal environment in fall during operating hours. 


\section{B. Usage conditions of personal underfloor air outlet system}

Fig. 7 shows the boxplot of the usage rate and maximum outdoor air temperature. In the summer, the usage rate was very high. However, with a drop in the outdoor temperature in fall, some workers tended to decrease their usage rate. Fig. 8 shows the relationship between the number of operations per hour for one person and the usage rate in one day for one person each season. In these results, more than 75 percent of those surveyed used the personal underfloor air outlet system over 80 percent of the time during many hours in summer. However, the number of operations of the personal underfloor air outlet system per hour was often less than one. It is

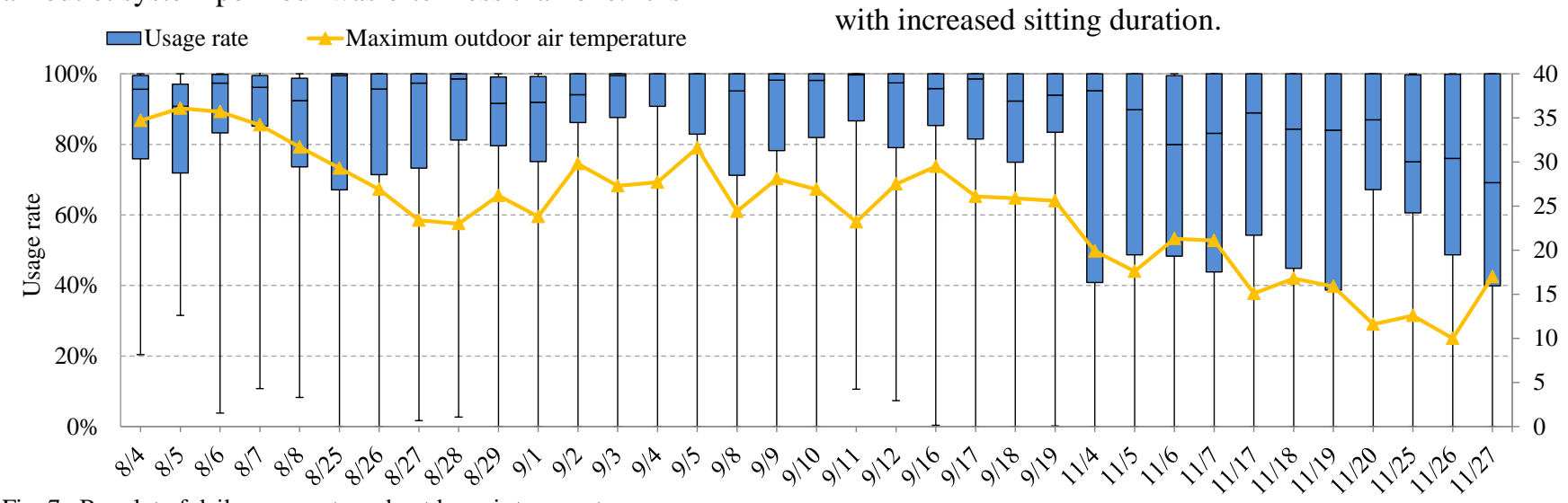

Fig. 7. Boxplot of daily usage rate and outdoor air temperature.

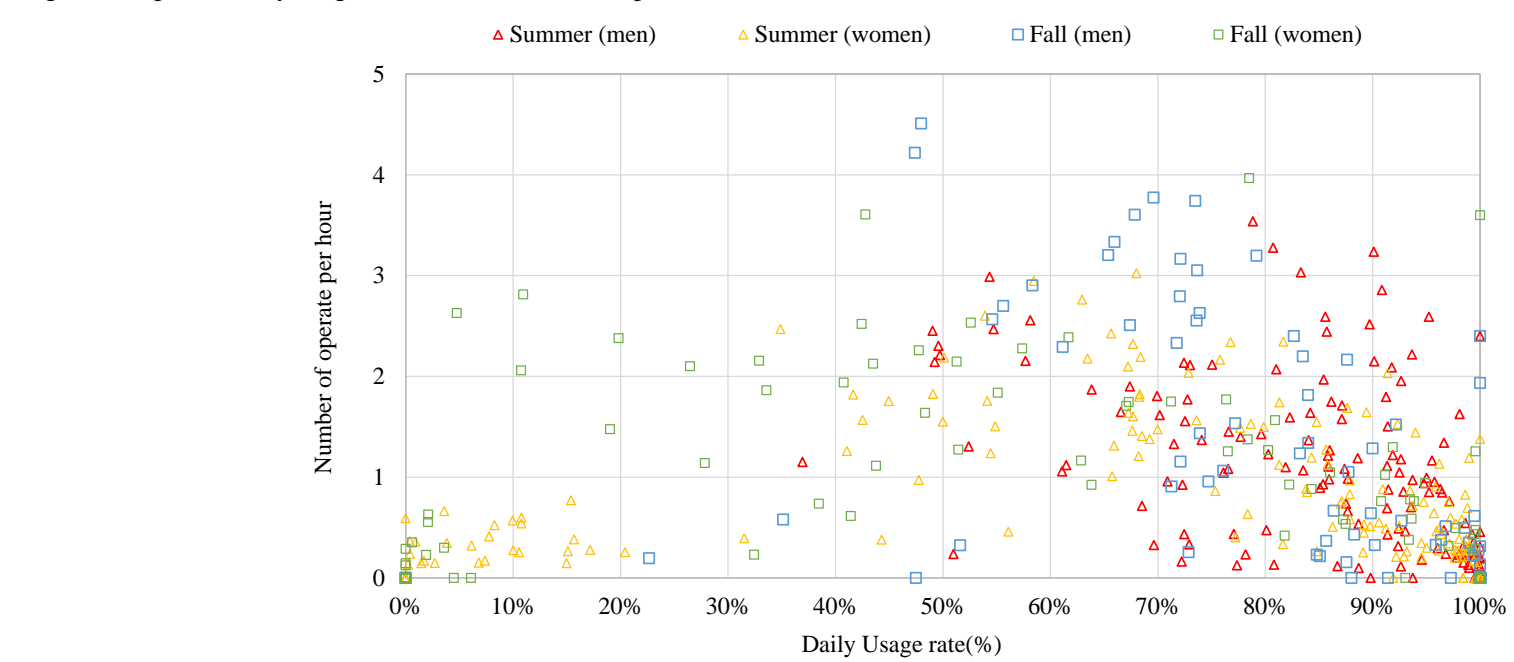

Fig. 8. Relationship between number of operations per hour for one person and usage rate in one day for one person each season. believed that the personal underfloor air outlet system was used continually by workers in summer. On the other hand, more than 75 percent of those surveyed used the personal underfloor air outlet system more than 50 percent of the time during many hours in fall. In these results, the usage rate of the personal underfloor air outlet system was low compared to summer. However, the number of daily operations of the personal underfloor air outlet system tended to increase compared to summer. Also, some female workers never operated the personal air-conditioning system. Moreover, Figs. 10 and 11 show the usage rate by sitting duration for each season. The usage rate of some workers tended to decrease with increased sitting duration.

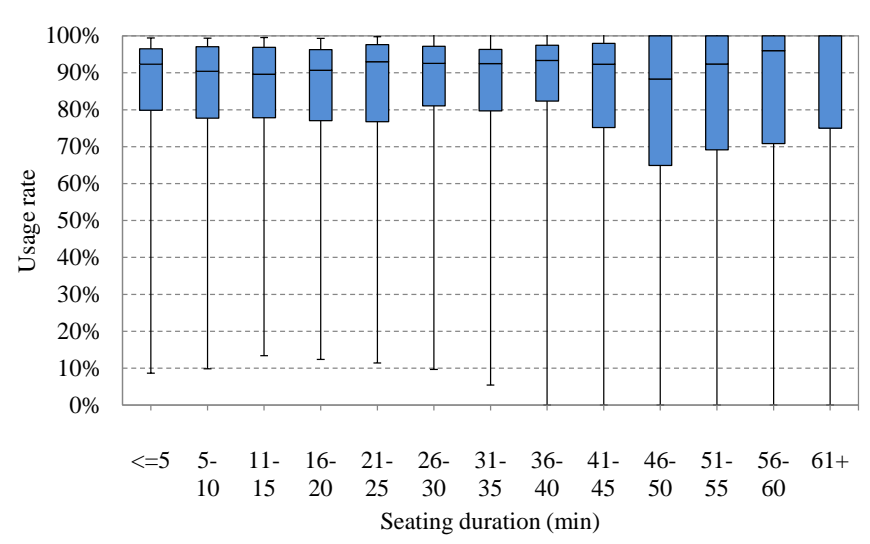

Fig. 10. Usage rate by sitting duration in summer.

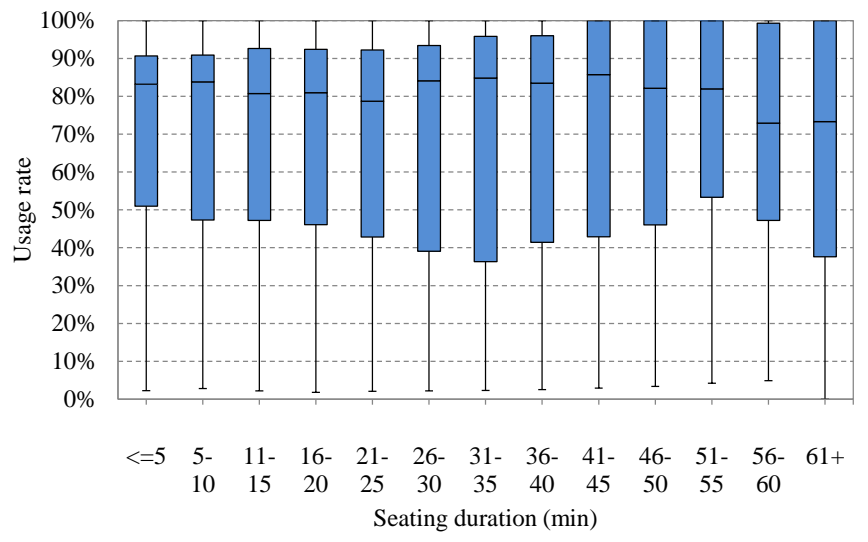

Fig. 11. Usage rate by sitting duration in fall. 


\section{Individual usage rates and satisfaction with the personal underfloor air outlet system}

Figs. 12 and 13 show the individual usage rates and satisfaction with the personal underfloor air outlet system in each season. Table VI shows the explanatory notes for the various degrees of satisfaction. Numbers M1-M10 represent the men, whereas W1-W10 represent the women. Many of the workers expressed a high degree of satisfaction and had a high usage rate. However, some workers expressed a low degree of satisfaction. The reason for male dissatisfaction seemed to be related to the lack of air volume. The reason for female dissatisfaction was that their feet overcooled due to free movement of the opened personal underfloor air outlet system. Moreover, Fig. 14 shows a comparison of the satisfaction with the personal underfloor air outlet system in summer and fall. In fall, the usage rate is low compared to summer. Also, satisfaction with the personal underfloor air outlet system somewhat declined. It is believed that the main cause of dissatisfaction was the low temperature air supply $\left(25^{\circ} \mathrm{C}\right)$.

\section{Temperature-humidity range deemed unacceptable}

Figs. 15 and 16 show the data based on ASHRAE Standard 55-2004, as it relates to the temperature and humidity comfort range within which subjects felt the environment was unacceptable each season. The small red points represent indoor thermal environments during seated times in the summer. These results show that 153 votes indicate an unacceptably hot environment. Also, 15 votes indicate an unacceptably cold environment. The unacceptable votes per day are 6.4 votes for a hot environment and 0.6 votes for a cold environment. However, some workers reported that the environment was unacceptably hot despite use of the personal underfloor air outlet system, and they expressed this even when the temperature and humidity were within a comfortable range. Therefore, we must also consider that the acceptability of the thermal environment is not simply determined by temperature, humidity, and airflow. In fall, the blue points represent indoor thermal environments during seated times in the fall. These results show that 31 votes indicate an acceptable environment. Furthermore, 22 votes indicate an unacceptably cold environment. The unacceptable votes per day are 2.8 votes for a hot environment and 2 votes for a cold environment. In these results, the unacceptable votes are fewer compared to summer.

\section{E. Occurrence frequency of the operative temperature at which the environment was deemed unacceptable}

Figs. 17 and 18 show the occurrence frequency of operative temperature deemed unacceptable by the workers each season. The bar chart in the figure indicates the occurrence frequency of the operative temperature during seated times, as recorded by the Ostracon. In these results, in summer, the occurrence frequency of both "hot" and "cold" votes indicating an unacceptable environment is similar to that for the operative temperature during sitting times. Therefore, the data do not show a relationship between temperature and acceptability of the thermal environment. In fall, the votes for an unacceptably hot environment are concentrated on the hot environment side.
Also, the votes for an unacceptably cold environment are concentrated on the cold environment side.

\section{F. Frequency of complaints by sitting duration}

Figs. 19 and 20 show the frequency of complaints by sitting duration for each season. In these results, in summer, reports of an unacceptably hot environment are concentrated immediately after the start of sitting and after a long sitting time. Moreover, reports by women of an unacceptably cold environment are concentrated after sitting for a long time. On the other hand, in fall, reports of an unacceptably cold environment are concentrated after a long sitting time.

TABLE VI

EAPLANATORY NOTES OF DEGREE OF SATISFACTION

\begin{tabular}{c|c} 
& Degree of satisfaction with personal underfloor air outlet system \\
\hline \hline 6 & Very satisfied \\
\hline 5 & Satisfied \\
\hline 4 & Somewhat satisfied \\
\hline 3 & Somewhat dissatisfied \\
\hline 2 & Dissatisfied \\
\hline 1 & Very dissatisfied
\end{tabular}

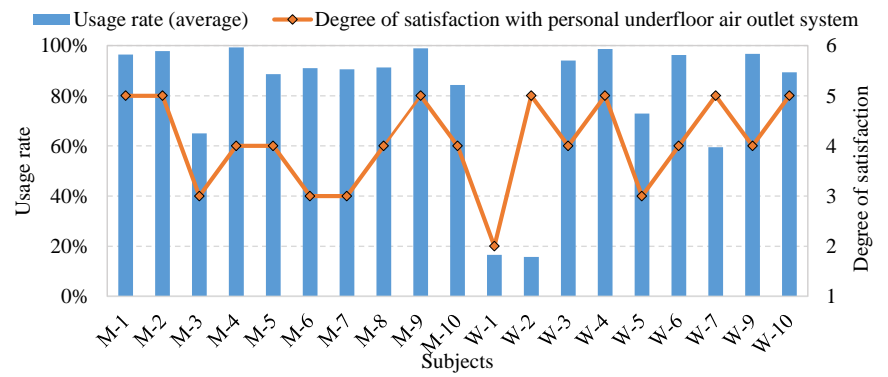

Fig. 12. Individual usage rate and satisfaction with the personal underfloor air outlet system in summer.

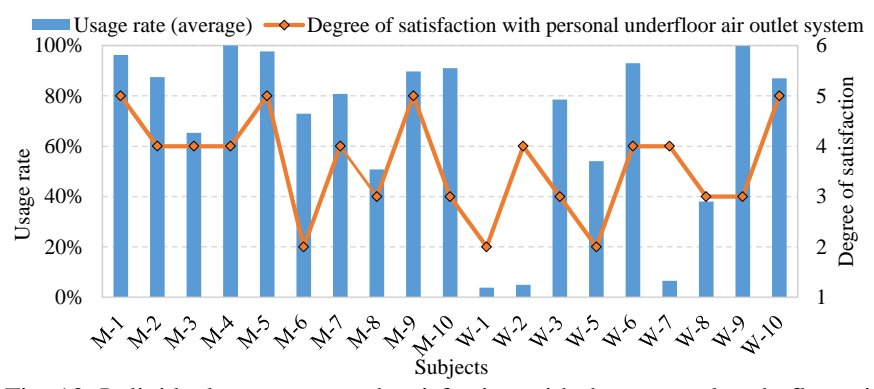

Fig. 13. Individual usage rate and satisfaction with the personal underfloor air outlet system in fall.

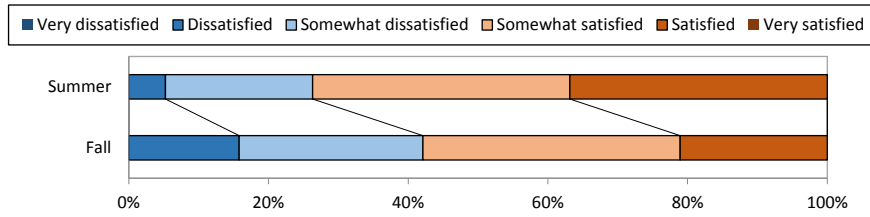

Fig. 14. Satisfaction comparison between summer and fall. 


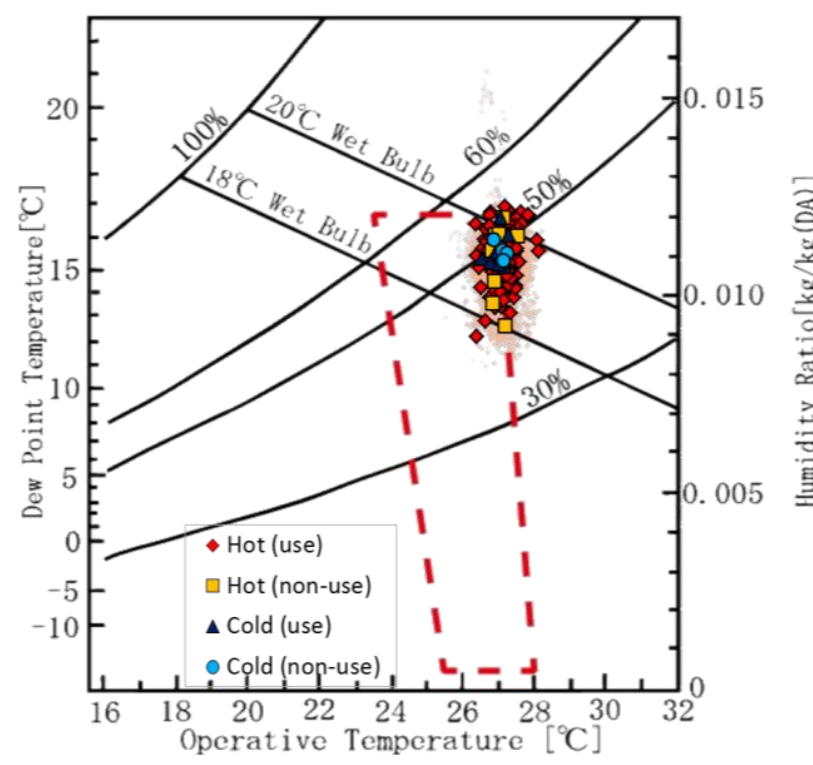

Fig. 15. Voting points on the comfortable temperature-humidity range indicating an unacceptable environment (ASHRAE Standard 55-2004) in summer.

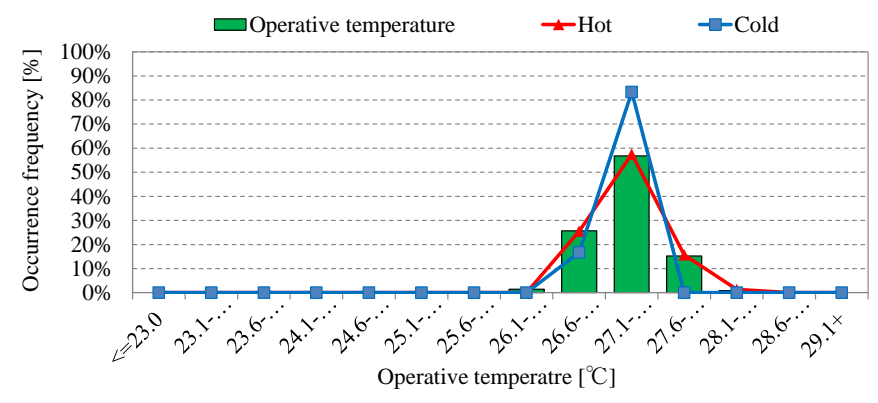

Fig. 17. Occurrence frequency of the operative temperature at which the environment was deemed unacceptable by workers in summer.

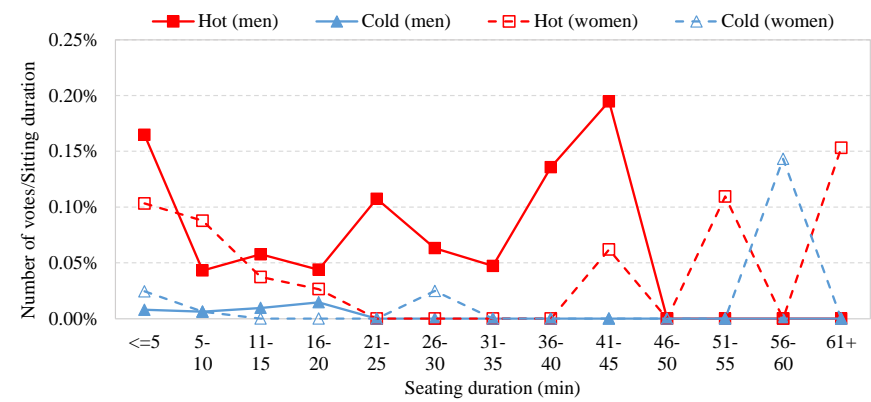

Fig. 19. Frequency of complaints by sitting duration in summer.

\section{DISCUSSION}

In summer, the usage rate of the personal underfloor air outlet system was very high, and most workers were satisfied with the system's effect. However, some workers reported that the environment was unacceptable despite the use of the system, and they expressed this even when the temperature and humidity were within a comfortable range. However, some workers reported that the environment was unacceptably hot despite the use of the system, and they expressed this even when the temperature and humidity were within a comfortable range. Also, reports of an unacceptably hot environment were

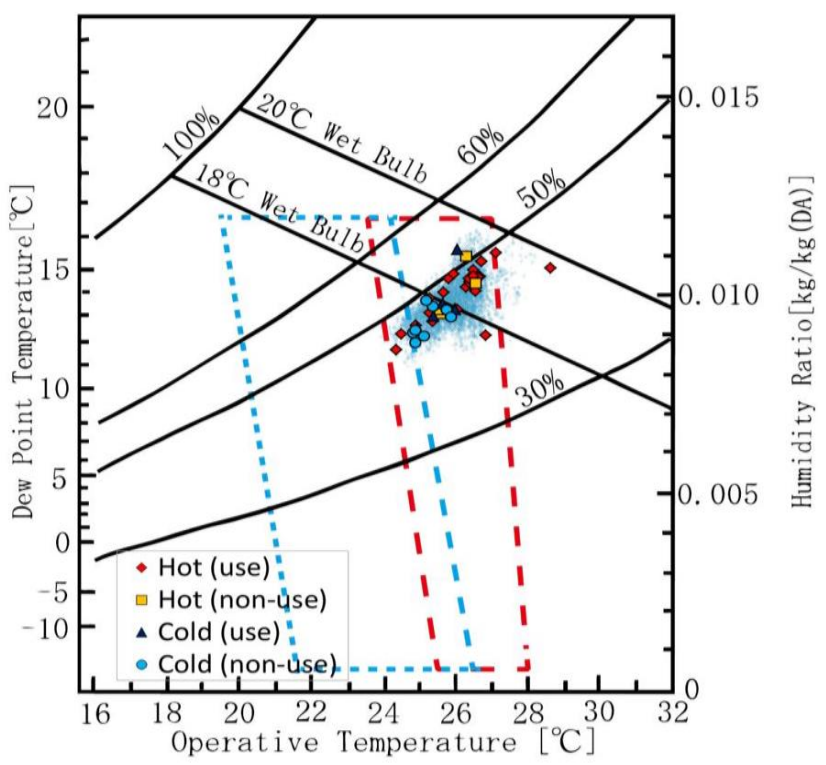

Fig. 16. Voting points on the comfortable temperature-humidity range indicating an unacceptable environment (ASHRAE Standard 55-2004) in fall.

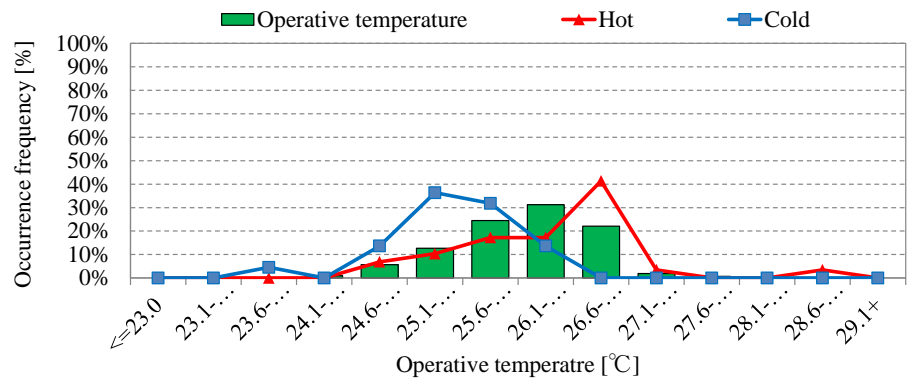

Fig. 18. Occurrence frequency of the operative temperature at which the environment was deemed unacceptable by the workers in fall.

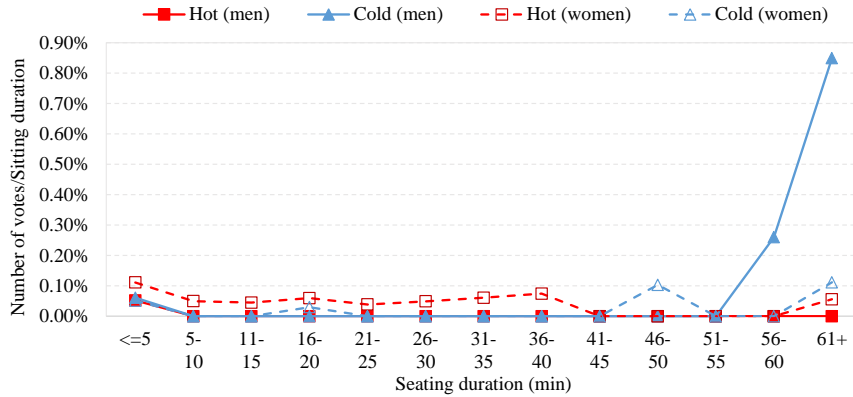

Fig. 20. Frequency of complaints by sitting duration in fall.

concentrated immediately after the start of sitting and after long sitting times. Therefore, it is believed that the votes for an unacceptably hot environment after the start of sitting are not simply determined by temperature, humidity, and airflow. Moreover, the cause of complaints by workers sitting for a long time was that the indoor thermal environment was preset at a high level.

Compared to summer, the fall usage rate and satisfaction with the personal underfloor air outlet system show a slightly decreasing trend. However, it is believed that the personal underfloor air outlet system was used as needed by workers 
because the number of daily operations of the personal underfloor air outlet system tended to increase compared to summer. Also, the unacceptable votes show a slightly decreasing trend compared to summer. However, the votes for an unacceptably hot environment are concentrated on the hot environment side, whereas the votes for an unacceptably cold environment are concentrated on the cold environment side. Therefore, it is believed that the complaints in fall are in relation to the indoor thermal environment.

From the above results, it is believed that there are two types of complaints in summer. The first type seems to be influenced by factors other than the office environment, such as changes in metabolic rate and the individual's thermal history upon returning to the office following outdoor activities. The second type is related to the indoor thermal environment such as the occurrence of complaints from workers sitting for a long time. On the other hand, in fall, there is only one type of complaint related to the indoor thermal environment such those from workers sitting for a long time. It is believed that individual thermal history and changes in metabolic rate are not related to complaints on indoor thermal environment because workers did not perspire to the same extent in fall.

Therefore, it is believed that the air volume of the personal underfloor air outlet system is not sufficient to compensate for an individual's thermal history obtained outside the office in summer. However, it could be appropriate for use either for an extended period of time or only in fall.

\section{CONCLUSIONS}

This study was aimed to clarify the usage of a personal airconditioning system called the personal underfloor air outlet system and to describe the characteristics of actual worker acceptance of the thermal environment through data captured by the Ostracon voting device. This device was developed to record the physical environment when a worker presses a button to register a complaint. To achieve these aims, we developed a usage recording device that records the usage conditions when workers operate the personal underfloor air outlet system. The usage recording device was employed in the usage survey of the personal underfloor air outlet system for 20 workers in summer and fall. Moreover, the Ostracon was used to measure whether workers felt that the thermal environment was acceptable.

The results show that the usage rate of the personal underfloor air outlet system was very high, and most workers were satisfied with the system's effect. Only a few workers reported that the environment was unacceptable despite the use of the system, and they expressed this even when the temperature and humidity were within a comfortable range in summer. Therefore, we consider that the acceptability of the thermal environment is not simply determined by temperature, humidity, and airflow. However, we observed that workers' complaints were often expressed at the moments after returning from tasks performed outside the office, suggesting that their complaints were influenced by factors other than the office environment, such as changes in metabolic rate and individual thermal history. Moreover, it is believed that the air volume of the personal underfloor air outlet system is not sufficient to compensate for an individual's thermal history obtained outside the office in summer. However, it could be appropriate for use either for an extended period of time or only in fall.

\section{REFERENCES}

[1] H. Koh, M. Ukai, and T. Nobe, "THE PERFORMANCE VERIFICATION OF DESICCANT AIR HANDLING SYSTEM OF S CORPORATE," Grand Renewable energy 2014 International Conference and Exhibition, July, 2014, Tokyo, Japan,

[2] M. Ukai, Y. Ichikawa, and T. Nobe, "Field Study of Thermal Environment Acceptability Using Ostracon Voting Device," WINDSOR CONFERENCE 2014, April, 2014, Windsor, United Kingdom.

[3] S. Kuno, "A two-dimensional model expressing thermal sensation in transitional conditions," ASHRAE Trans., vol. 93, pt. 2, pp 396-406, 1987.

[4] Y. Nishi and T. Nakayama, ed., Chapter 2, "Heat exchange between the human body and environment," pp.33, Rikogakusha, 1981

[5] A. P. Gagge, J. A. J. Stolwijk, and J. D. Hardy, "Comfort and thermal sensations and associated physiological responses at various ambient temperatures," Environmental Research. vol. 1, pt. 1, 1967. http://dx.doi.org/10.1016/0013-9351(67)90002-3

[6] M. Ukai and T. Nobe, "Study on Acceptability in Unsteady Environment," 9th International Meeting for Manikins and Modeling, Tokyo, Japan, August, 2012

[7] T. Nobe, S. Tanabe, S. Lee, Y. Tomioka "Investigation of Seat Occupancy Rate in Office," ROOMVENT 2002 Proceedings, September 2002, pp 289-292, Copenhagen, Denmark. 